\title{
Optical Measurement of Surface Temperature Distribution of Weld Pool in AC Tungsten Inert Gas Welding of Aluminum A1050
}

\author{
Quang Ngoc TRINH* , Huy Le PHAN*,**, Shinichi TASHIRO** \\ Van Hanh BUI* and Manabu TANAKA**
}

(Received March 15, 2019)

\begin{abstract}
When alternating current (AC) is used in tungsten inert gas (TIG) welding, the shape of weld penetration is known to be largely changed depending on electrode positive (EP) polarity ratio which is defined as a ratio of EP period occupied in one cycle of current waveform. This fact implies that heat transport processes between electrode negative (EN) and EP polarity are significantly different to lead to different temperature distribution of weld pool. However, these processes have not been understood clearly, because they are thought to be directly linked to the complex cathode spot behavior. This study aims to discuss difference in heat transport processes between EN and EP polarity in AC TIG welding of aluminum A1050 by comparing temperature distributions in both polarities measured with two colour pyrometry taking into account the cathode spot behavior. As a result, it was found that the temperatures at the center in EN were greater than that in EP and decreased gradually toward the edge of the weld pool. Moreover, the temperature in $30 \%$ EP polarity ratio was higher than that in $10 \%$ EP polarity ratio. Consequently, the heat flux produced by cathode spots is suggested to significantly affect the surface temperature distribution of weld pool as well as the weld shape. The heat flux distribution in EP polarity is considered to become not Gaussian but ring-shaped. Furthermore, the reason to achieve higher average temperature in $30 \%$ EP polarity ratio is explained by longer heating through cathode spots.
\end{abstract}

Key Words: Optical Measurement, Surface Temperature, Weld Pool, AC TIG Welding, Aluminum

\section{Introduction}

Nowadays, aluminum and aluminum alloys increasingly become used widely in manufacturing industry because of their excellent physical properties such as lightweight and high electrical conductivity ${ }^{1)}$. However, aluminum welding still faces many challenges for example due to the high thermal conductivity of aluminum and oxide layer formation on the surface which has many different properties with the pure metal ${ }^{2}$. To overcome the latter problem, in Tungsten Inert Gas (TIG) welding, the alternating current (AC) has been generally used for employing cleaning effect to the oxide layer by cathode spots during electrode positive (EP) polarity. When AC is used, the shape of weld penetration is known to be largely changed depending on EP polarity ratio which is defined as a ratio of EP period occupied in one cycle of current waveform ${ }^{3), 4)}$.

The above fact implies that heat transport processes between EN and EP polarity are significantly different to lead to different temperature distribution of weld pool. In normal TIG welding with direct current electrode negative (DCEN) polarity, heat transport processes from the welding arc to the weld pool are already studied well and reported in many research papers ${ }^{5), 6)}$. However, in case of AC TIG welding, the heat transport processes have not been clarified especially for EP polarity, because the processes are considered to be strongly governed by the complex cathode spot phenomena.

In order to discuss the heat transport process described in the above, acquisition of the detailed information on weld pool temperature is indispensable. Until now, only a small number of study on weld pool temperature in arc welding aluminum was reported $^{7,8)}$. For example, in Metal Inert Gas (MIG) welding of aluminum, the weld pool temperature of around $1000^{\circ} \mathrm{C}$ was obtained by infrared light measurement ${ }^{9)}$. On the other hand, the maximum temperature was reported to increase up to 2000 $\mathrm{K}^{10)}$. This information is thought to be useful to discuss the heat transport process in weld pool in MIG welding of aluminum. However, the weld pool temperature in TIG welding of aluminum, especially, with the helium shielding gas is still not yet reported.

In EN polarity, the weld pool to be the anode collects electrons. So, heat transport from arc to weld pool is mainly carried out by thermal conduction and electron condensation. In contrast, in EP polarity, the weld pool becomes non-thermionic cathode accompanied with a large number of irregularly moving cathode spots. It is reported that each cathode spot has current of around 10 A, even though its average size is only several $\mu \mathrm{m}^{11), 12)}$. Therefore, current density in the cathode spot is expected to exceed an order of $10^{11} \mathrm{~A} / \mathrm{m}^{2}$ in some cases ${ }^{13),}{ }^{14)}$. It is considered to cause significant Joule heating due to higher current density and intensive heating

* Hanoi University of Science and Technology (306-C1 building-No.1-Dai Co Viet street, Hanoi, Vietnam) * * Joining and Welding Research Institute, Osaka University (11-1Mihogaoka, Ibaraki, Osaka 567-0047, Japan) 
by ion current. Accordingly, the significance of heat input in EP polarity than that in EN polarity is predicted. However, the above phenomena have not been understood clearly, because they are thought to be directly linked to the complex cathode spot behavior.

This study aims to discuss difference in heat transport processes between EN and EP polarity in AC TIG welding of aluminum A1050 by comparing temperature distributions in both polarities measured with two colour pyrometry similarly with Yamazaki et $a l^{15)}$ taking into account the cathode spot behavior.

\section{Experimental methods}

It is well-known that thermocouples have been generally used to record the welding thermal cycle for experimental purposes because of its simplicity, but it has many disadvantages such as requiring time for achieving the thermal equilibrium between a thermocouple and an object, and the upper limit of temperature range for measurement which is determined by the melting point of the thermocouple. In contrast, non-contact type temperature measurement by radiation thermometry is known to have much more advantages for obtaining the surface temperature distribution without any disturbance to the temperature of a measured object. In this research, two colour pyrometry is used to measure the temperature of a weld pool in AC TIG welding. Two wavelengths of 950 and $980 \mathrm{~nm}$ in the infrared range are selected to sufficiently lower the effect of the arc plasma radiation.

\subsection{Measurement principles}

The two colour pyrometry is a temperature measurement method that selects two different wavelengths of light emitted from a measured object. The temperature is determined from the ratio of radiation intensity at two wavelengths, based on the Plank's radiation law expressed as equation (1).

$$
\frac{I_{1}}{I_{2}}=\frac{\varepsilon_{1}}{\varepsilon_{2}}\left(\frac{\lambda_{2}}{\lambda_{1}}\right)^{5} \frac{1-\exp \left(C_{b} / \lambda_{2} T\right)}{1-\exp \left(C_{b} / \lambda_{1} T\right)}
$$

Where $I_{1}, I_{2}$ are radiation intensities $\left(\mathrm{W} \mathrm{m}^{-3} \mathrm{sr}^{-1}\right) ; \varepsilon_{1}, \varepsilon_{2}$, are emissivities; $\lambda_{1}, \lambda_{2}$ are wavelengths $(\mathrm{nm}) ; \mathrm{C}_{\mathrm{b}}=0.014388 \mathrm{mK}$; and $T$ is temperature $(\mathrm{K})$. When Wien's approximation is applied and the emissivity is assumed to be the same for the selected wavelengths, equation (1) is deformed to equation (2).

$$
\frac{I_{1}}{I_{2}}=\left(\frac{\lambda_{2}}{\lambda_{1}}\right)^{5} \frac{\exp \left(C_{b} / \lambda_{2} T\right)}{\exp \left(C_{b} / \lambda_{1} T\right)}
$$

From this equation, $T$ can be expressed by the following formula (3); that is, the temperature of the object can be derived from the radiation intensity ratio at the two wavelengths.

$$
T=\frac{C_{b}\left(\lambda_{1}-\lambda_{2}\right)}{\lambda_{1} \lambda_{2}} \frac{1}{\ln \left(I_{1} \lambda_{1}^{5 /} I_{2} \lambda_{2}^{5}\right)}
$$

\subsection{Experimental apparatus for two colour pyrometry}

A schematic of the optical system for two colour pyrometry is shown in Fig. 1. In this system, the thermal emission light emitted from a high temperature weld pool passes through an object lens and a relay lens before divided by a dividing mirror. After passing two interference filters, the light formed an image on the sensor of a high speed camera.

\subsection{Experimental setup}

Overall schematic of experimental setup in the research is shown in Fig. 2. In this experiment, a stationary helium TIG arc is generated on an aluminum A1050 plate with $10 \mathrm{~mm}$ thickness. The welding current is $200 \mathrm{~A}$, the diameter of a tungsten electrode is $3.2 \mathrm{~mm}$ with an electrode extension of $5 \mathrm{~mm}$ and the arc length is $4 \mathrm{~mm}$. The welding current is turned off to extinguish the arc immediately after the arcing period of $3 \mathrm{~s}$. In order to investigate influence of EP polarity ratio on surface temperature distribution of weld pool, two kinds of EP polarity ratio are used. All common welding conditions are shown in Table $\mathbf{1 .}$

As shown in Fig. 2, a TIG welding power source (Daihen, DA300P) supplies a voltage signal to a delay timer immediately after starting arc through welding current relay (WCR) to count arc time. The clamp meter (HIOKI, 3285) measures the current waveform and send it to the data logger (KEYENCE, NR-500/ NR-HV04) with the acquisition frequency of $0.5 \mathrm{MHz}$. The current waveform measurement and high-speed camera observation are carried out with a delay time of 3 seconds from the beginning of

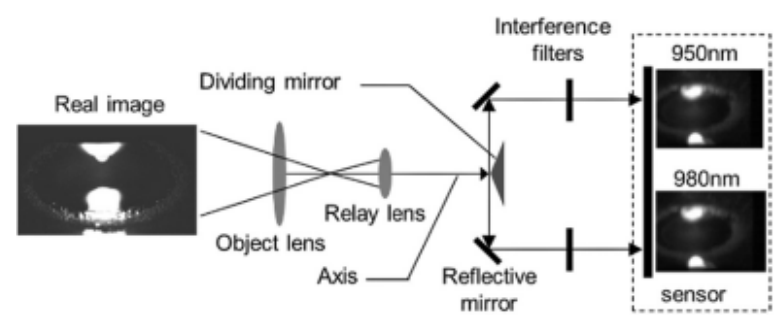

Fig. 1 Schematic of optical system for two colour pyrometry.

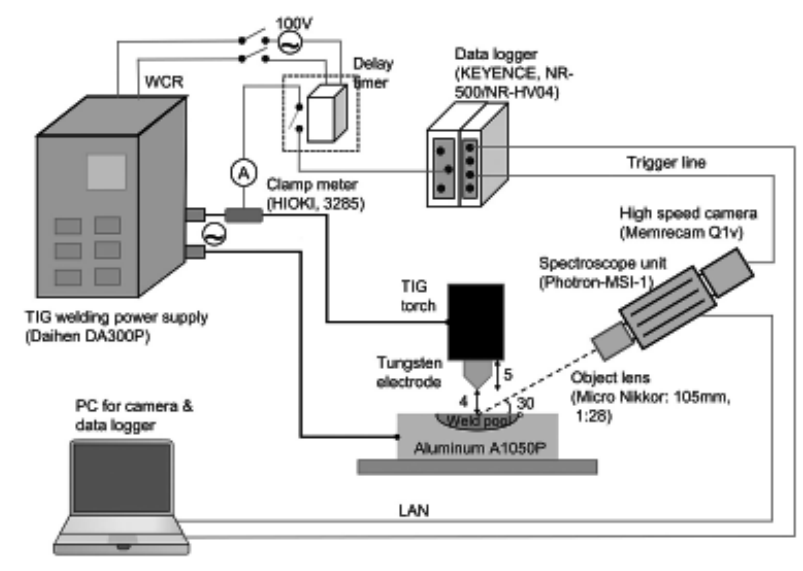

Fig. 2 Experimental setup. 
Table 1 Common welding conditions.

\begin{tabular}{|l|l|l|}
\hline Parameters & Value & Unit \\
\hline Base metal & Aluminum 1050 & \\
\hline Thickness of base metal & 10 & $\mathrm{~mm}$ \\
\hline Welding current & 200 & Ampere \\
\hline Current polarity & AC & \\
\hline Arc time & 3 & Second \\
\hline EP ratio & $10 ; 30$ & $\%$ \\
\hline Arc length & 4 & $\mathrm{~mm}$ \\
\hline Shielding gas & Helium & \\
\hline
\end{tabular}

Table 2 Observation conditions.

\begin{tabular}{|l|l|l|}
\hline Parameters & Value & Unit \\
\hline Camera & Memrecam Q1v & \\
\hline Band pass filter & $950 ; 980$ & $\mathrm{~nm}$ \\
\hline Frame rate & 500 & $\mathrm{fps}$ \\
\hline Expose time & 2 & $\mathrm{~ms}$ \\
\hline
\end{tabular}

\section{(a) $30 \% \mathrm{EP}$}

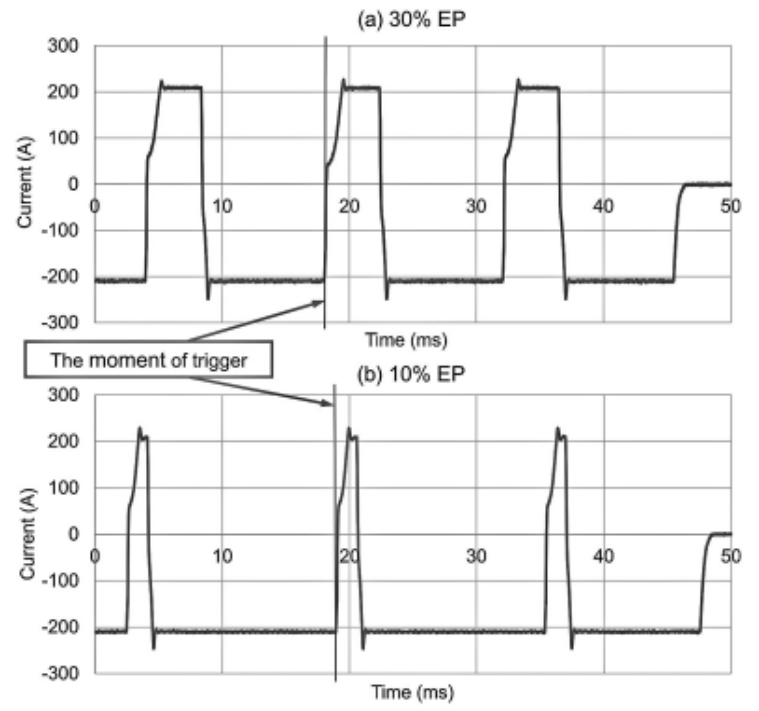

Fig. 3 Current waveform in EP polarity ratio of (a) $30 \%$ and (b) $10 \%$.

the arc by delay timer. The observation time is synchronized with arc by trigger line from the data logger to the camera. The results are recorded by a personal computer. A spectroscope unit (Photron, MSI-1) with two band-pass filters for $950 \mathrm{~nm}$ and $980 \mathrm{~nm}$ is used with an object lens (Nikon, Micro Nikkor) having $105 \mathrm{~mm}$ focal length and $1 / 28$ focus ratio. The frame rate of high-speed camera is $500 \mathrm{fps}$ and the exposure time is $2 \mathrm{~ms}$. Weld pool images are recorded by the high-speed camera from the upper direction at the inclination angle of $60^{\circ}$ against the perpendicular line. The observation conditions are summarized in Table 2.

Fig. 3 shows the current waveform when the ratios of the EP polarity are 30 and 10 percentages. To determine accurately the moment of temperature measurement, it is necessary to synchronize the measurement time with the current waveform.
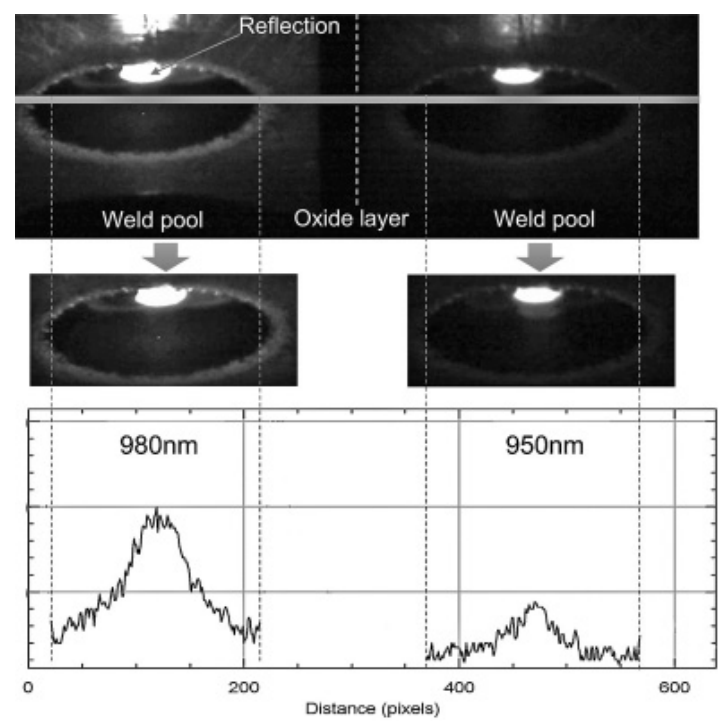

(a)

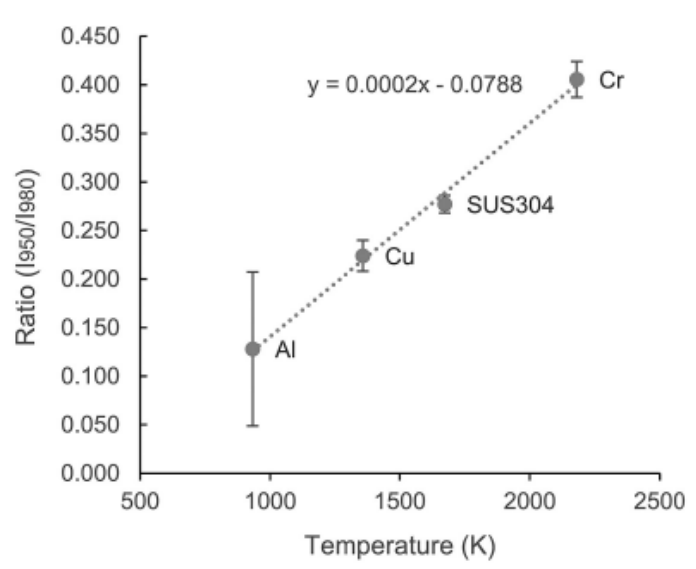

(b)

Fig. 4 (a) Observation of the weld pool surface at the beginning of EP polarity and (b) the calibration graph.

For this purpose, a trigger signal is transmitted from the data logger to the camera and also to the computer for counting the time. The frequency of $\mathrm{AC}$ is $70 \mathrm{~Hz}$, it means that the duration of one current cycle is approximately $14 \mathrm{~ms}$. Meanwhile, the frame rate of camera is $500 \mathrm{fps}$ and the exposure time is $2 \mathrm{~ms}$. As shown in the Fig. 3, the red lines define the synchronous moments between the observation time and the welding arc time. The temperature distribution on the surface of weld pool is obtained as a function of radial distance from the center of the weld pool. In addition, time variation in temperatures at the center of the weld pool is also discussed. The average arc voltages were $28.9 \mathrm{~V}$ and $12.2 \mathrm{~V}$ in EP and EN polarity, respectively.

\section{Experimental results and discussion}

Fig. 4 (a) shows an example of the weld pool surface image at the beginning of EP polarity observed by the high speed camera through two filters. The image was processed using 
ImageJ software. The observed image was divided into two parts corresponding to the images passing through two filters. The part showing higher brightness presented in the left side corresponds to the image at the wavelength of $980 \mathrm{~nm}$. A strong intensity region was seen around the upper edge of weld pool because of a reflection of the high-temperature tungsten electrode on the liquid metal. So, in order to exclude that effect, the region used for calculating the temperature is chosen enough far from the reflection of the electrode.

The gray values as function of horizontal position along the blue line in the upper figure are also shown in the lower figure. There is a difference of brightness correlated with measured location. Around the center of weld pool, gray values at the wavelength of $980 \mathrm{~nm}$ are much higher than those at the wavelength of $950 \mathrm{~nm}$. Outside the weld pool, the measurement of accurate temperature is thought be difficult, because of the presence of reflection at the edge of the aluminum oxide in solid state. Therefore, only the temperature in the weld pool is discussed in this study. The gray value corresponding to background noise was confirmed to be negligible level of around $0 \sim 1$.

The calibration result presenting a relationship between the sensitivity ratio at the wavelengths of 950 and $980 \mathrm{~nm}$ and temperature is shown on Fig. 4 (b). The sensitivity ratios were measured at the melting point of several metal and alloy: Aluminum (Al), Copper (Cu), Stainless steel (SUS304), and Chromium $(\mathrm{Cr})$. The ratios were taken at the edge of weld pool of each metals. Based on those experimental ratios, the pyrometry system was calibrated for assuring the accuracy of the temperature obtained on the weld pool of Al.

Fig. 5 shows the temperature distribution as a function of radial distance from the center of weld pool at the end of EN and EP in $30 \% \mathrm{EP}$ polarity ratio. It is obvious that the temperature at the center was higher than that near the edge of weld pool. Besides, at the end of EN polarity, the temperature at the center of weld pool was $2270 \mathrm{~K}$, which was higher than $1650 \mathrm{~K}$ at the end of EP polarity. The temperature difference was about $600 \mathrm{~K}$. Near the weld pool boundary, the temperature was almost the same between EP and EN polarity and found to be slightly higher than the melting point of aluminum. Therefore, the temperature gradient in $30 \% \mathrm{EN}$ was steeper than that in $30 \% \mathrm{EP}$.

Fig. 6 shows the time variation in temperature at the center of the weld pool and the time sequential images of weld pool in one current cycle in $30 \%$ EP polarity ratio. The temperature in EN polarity was seen to be clearly higher than that in EP polarity and almost the constant value of around $2100 \mathrm{~K}$. It gradually decreased during EP polarity and finally reached approximately $1600 \mathrm{~K}$ at the end of EP polarity. One of the reasons is considered to be related to the cathode spot phenomenon in EP polarity.

The temperature distribution as a function of radial distance

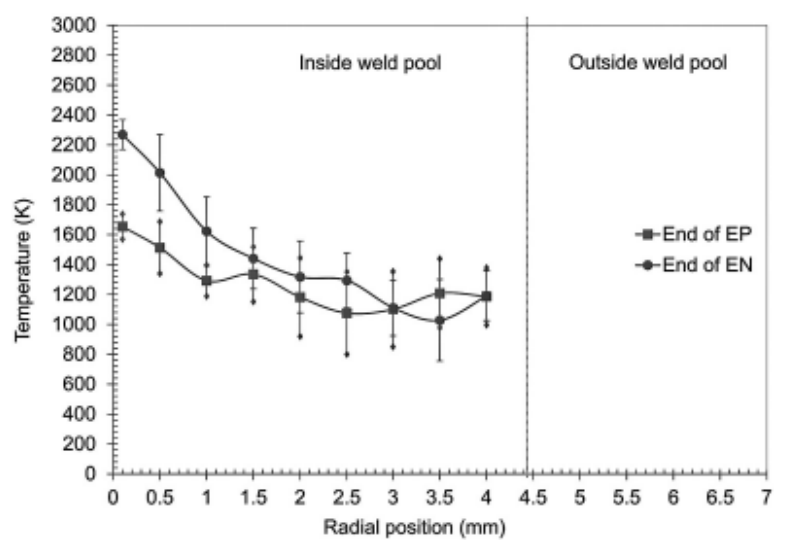

Fig. 5 Temperature of the weld pool surface at the end of EN and EP in $30 \%$ EP polarity ratio.

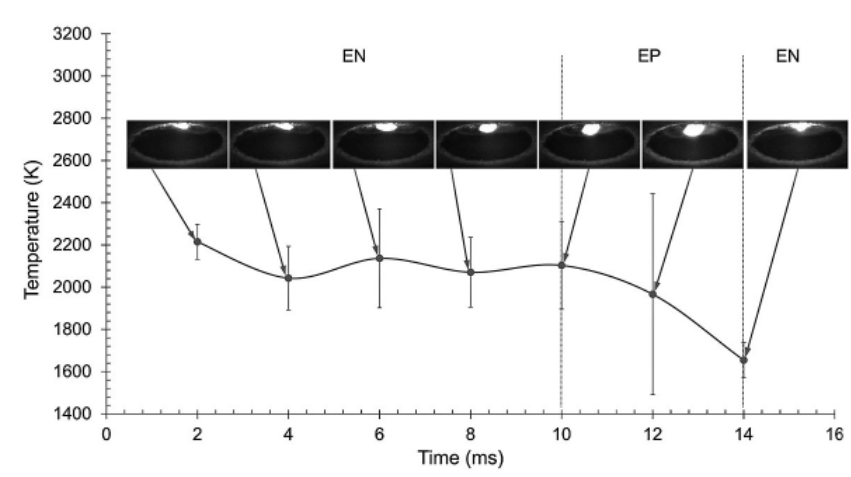

Fig. 6 Time variation in temperature at the center of the weld pool and the time sequential images of weld pool in one current cycle in $30 \%$ EP polarity ratio.

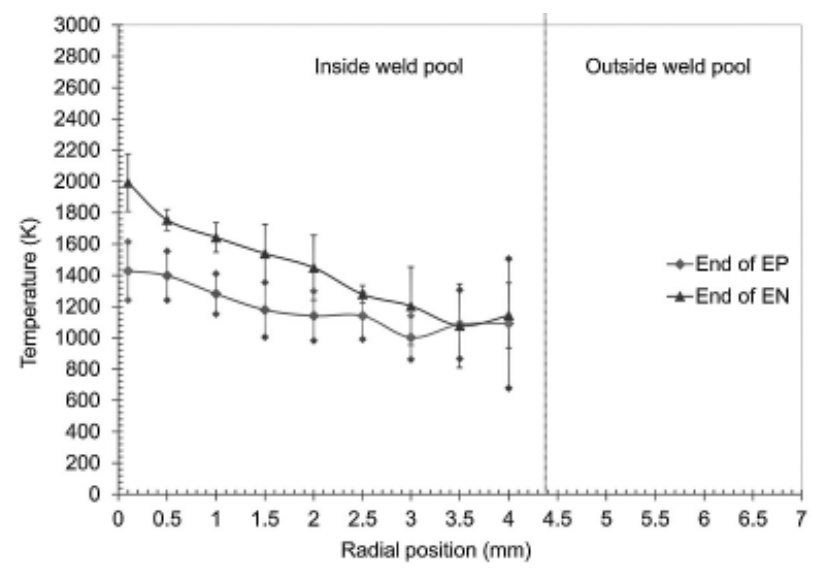

Fig. 7 Temperature distribution as a function of radial distance from the center of weld pool at the end of EN and EP in $10 \%$ EP polarity ratio.

from the center of weld pool at the end of EN and EP in $10 \%$ EP polarity ratio is shown in Fig. 7. The temperature at the end of EN polarity was approximately $2000 \mathrm{~K}$. Otherwise, that was $1400 \mathrm{~K}$ at the end of EP polarity. However, the EP duration of $10 \% \mathrm{EP}$ ratio is about $1.4 \mathrm{~ms}$ under this experimental condition, so it is shorter than the exposure time $(2 \mathrm{~ms})$ used in the 
experiment. It means the measured temperature in the end of EP was considered to involve an effect of DCEN arc. The DCEN arc, which constricted in the center ${ }^{5)}$, could lead the central temperature of weld pool higher than that in the EP polarity. Therefore, the central surface temperature at the end of EP in Fig. 7 is thought to be higher than the actual temperature. The results show that although the temperature difference was approximately $600 \mathrm{~K}$ which was similar with the result in Fig. 5, the average temperature was thought to be lower in this case.

Fig. 8 shows appearance of arc, weld pool and cathode spots in 10 and $30 \%$ EP polarity ratio. In EN polarity, the arc was found to be stably constricted to the center of weld pool. This arc constriction leads to higher heat flux from the arc to weld pool through thermal conduction and electron condensation. As a result of this, temperature around the center increased up to around 2270 $\mathrm{K}$ and $2000 \mathrm{~K}$ in $30 \%$ and $10 \% \mathrm{EP}$ polarity ratio, respectively. On the other hand, the cathode spots were found to be distributed in ring-shape avoiding the center of the weld pool in EP polarity. Phan et al found that this tendency was generally seen in helium TIG welding ${ }^{16)}$. It leads to the arc to be more diffusive, which is considered to reduce heat flux by thermal conduction around the center. Eventually, the temperature around the center is thought to be decreased gradually during EP polarity. A larger number of cathode spots was observed to arrive at the white zone placed outside of the weld pool in $30 \%$ EP polarity ratio than that in $10 \%$ EP due to longer EP polarity duration.

Fig. 9 shows bead appearance after welding in 10 and $30 \%$ EP polarity ratio. The width of white zone is larger in 30\% EP polarity ratio, which can be explained by difference in cathode spot distribution. The result also indicates that the diameter of weld pool in $30 \%$ EP is approximately $10 \mathrm{~mm}$, which is higher than the diameter of $8 \mathrm{~mm}$ in $10 \%$ EP polarity ratio. It could prove the average temperature to be reduced in $10 \%$ EP polarity ratio as shown in Fig. 7.
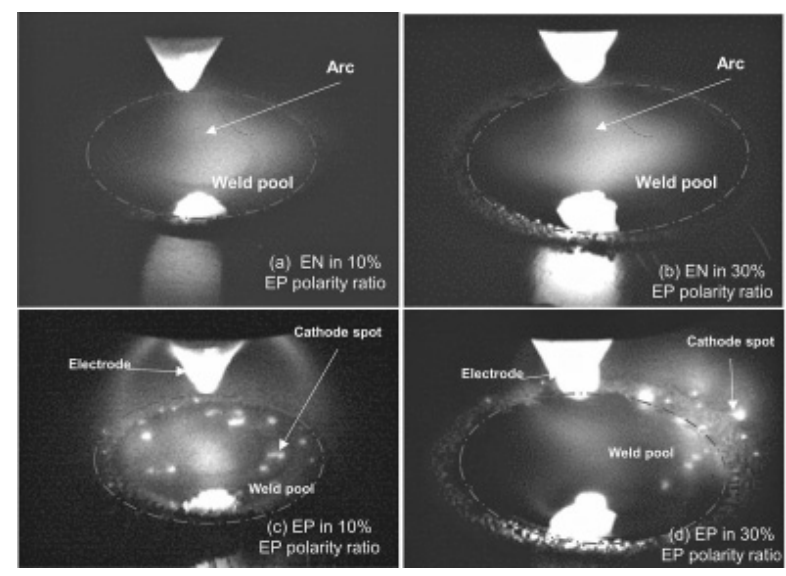

Fig. 8 Appearance of arc, weld pool and cathode spots in 10 and $30 \%$ EP polarity ratio.
Fig. 10 shows the cross-section of the weld bead in $10 \%$ and $30 \%$ ratio time of EP polarity. The weld penetrations in both cases were confirmed to be almost similar level of around $2.3 \mathrm{~mm}$. On the other hand, the weld width of $10 \mathrm{~mm}$ in $30 \%$ EP polarity ratio was found to be clearly greater than that of $8 \mathrm{~mm}$ in $10 \% \mathrm{EP}$ polarity ratio.

In aluminum welding, the heat transport by thermal conduction is known to be dominant comparing with that by convection in weld pool due to high thermal conductivity. To discuss the relationship between the heat flux distribution and the penetration, the schematic mechanism of the arc phenomenon in EN and EP polarity is shown in Fig. 11. In the EN polarity, the arc, which had the Gaussian heat flux distribution, led to the highest temperature at the center of weld pool surface. The weld pool penetration was considered to have the hemispherical shape as in Fig. 11 (a). However, in the EP polarity, the heat flux distribution in EP polarity didn't become Gaussian due to influence of heat input by cathode spots considered to consist of significant Joule heating due to higher current density exceeding an order of $10^{11}$ $\mathrm{A} / \mathrm{m}^{2}$ in some cases and intensive heat transport by ion current. The distribution of cathode spot group as in Fig. 8 (c) and (d) made the heat flux distribution by the EP arc to have ring-shape. Therefore, the central surface temperature of the weld pool at the end of EP polarity became lower than that at the end of EN polarity (Fig. 5 and Fig. 7). On the contrary, because the weld pool edge was strongly heated by the cathode spots, the weld pool became wide. Therefore, the weld pool penetration had the disk-shape as in Fig. 11 (b). The significance of heat input in EP polarity than that in EN polarity is also predicted by difference in arc voltages between EP and EN polarity.

The cross-section of weld bead in Fig. 10 is discussed more in detail. In case of $10 \%$ EP polarity ratio, the EN time is longer than that in $30 \%$ EP polarity ratio. It means that there is larger heat input in the center of weld pool. However, the maximum temperature could not be higher due to heat loss caused by the

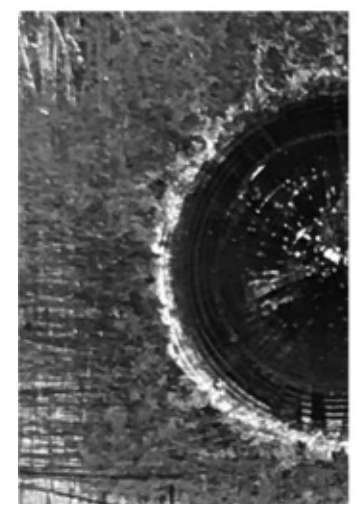

(a) $10 \%$ EP polarity ratio

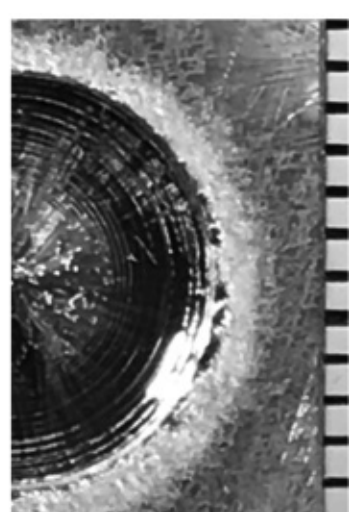

(b) $30 \%$ EP polarity ratio
Fig. 9 Bead appearance after welding in 10 and $30 \%$ EP polarity ratio. 


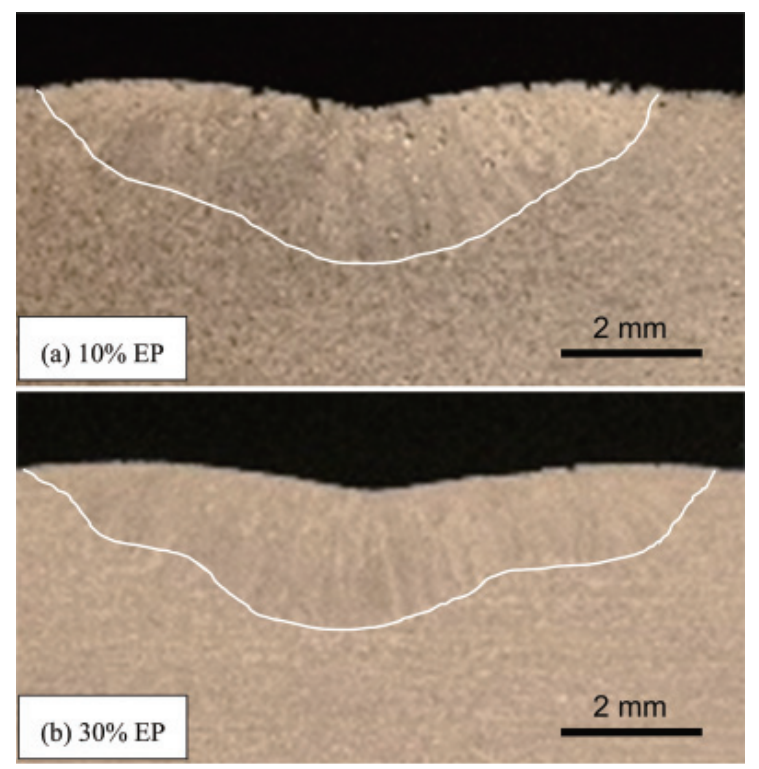

Fig. 10 Cross-section of the weld bead in $10 \%$ and $30 \%$ EP polarity ratio.

evaporation of aluminum, even though the heat input increased more. This is thought to make the depth of penetration to become almost same as or only slightly deeper than that in $30 \%$ EP polarity ratio. In addition, in $10 \% \mathrm{EP}$ polarity ratio, the EP time was shorter than that in $30 \% \mathrm{EP}$, so the distribution of cathode spots tends to be concentrated in a narrower area, which made the width of penetration in $10 \%$ EP polarity ratio is smaller than that in $30 \%$ EP polarity ratio. Consequently, the heat flux produced by cathode spots is suggested to significantly affect the surface temperature distribution of weld pool as well as the weld shape. Furthermore, the reason to achieve higher average temperature in $30 \%$ EP polarity ration is considered to be explained by longer heating through cathode spots.

\section{Conclusions}

In this paper, difference in heat transport processes between EN and EP polarity in AC TIG welding of aluminum A1050 was discussed by comparing temperature distributions in both polarities measured with two colour pyrometry taking into account the cathode spot behavior. As a result, it was found that the temperatures at the center in EN were greater than that in EP and decreased gradually toward the edge of the weld pool. Moreover, the temperature in $30 \%$ EP polarity ratio was higher than that in $10 \%$ EP polarity ratio. Consequently, the heat flux produced by cathode spots is suggested to significantly affect the surface temperature distribution of weld pool as well as the weld shape. The heat flux distribution in EP polarity is considered to become not Gaussian but ring-shaped. Furthermore, the reason to achieve higher average temperature in $30 \%$ EP polarity ration is explained by longer heating through cathode spots.

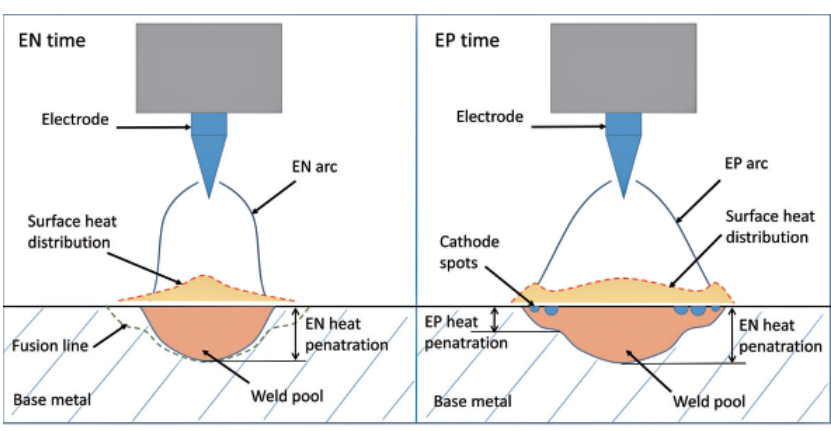

(a)

(b)

Fig. 11 Schematic mechanism of the arc phenomenon in (a) EN and (b) EP time.

\section{References}

1) G. Mathers: "The welding of Aluminium and its alloys", Woodhead Publishing Ltd, Cambridge, UK, (2002).

2) C. L. Jenney; A. O'Brien: “Welding Handbook", Ninth ed., (2015).

3) M. A. R. Yarmuch, B. M. Patchett: Welding Research, 86(2007)196200.

4) F. MIYASAKA, T. OKUDA, T. OHJI: Quarterly Journal of the Japan Welding Society, 22(2004)364-368.

5) M. Tanaka, J. J. Lowke: Journal of Physics D: Applied Physics, 40(2006)R1-R23.

6) M. Tanaka, K. Yamamoto, S. Tashiro, K. Nakata, E. Yamamoto, K. Yamazaki, K. Suzuki, A. B. Murphy, J. J. Lowke: Journal of Physics D: Applied Physics, 43(2010).

7) T. Hashimoto, F. Matsuda: Yosetsu Gakkai Shi/Journal of the Japan Welding Society, 34(1965)654-664.

8) S. Ohta, K. Asai, S. Ohya: Quarterly Journal of the Japan Welding Society, 8(1990).

9) Y. Su, X. Hua, Y. Wu, Y. Zhang, Y. Guo: Materials and Design, 78(2015)1-4.

10) A. Block-Bolten, T. W. Eagar: Metallurgical Transactions B, 15(1984)461-469.

11) B. Juttner: J. Phys., 34(2001)103-123.

12) S. A. Barengolts, G. a. Mesyats, D. L. Shmelev: 20th International Symposium on Discharges and Electrical Insulation in Vacuum, 31(2002)809-816.

13) A. E. Balanovskii: High Temperature, 56(2018)1-9.

14) G. A. Mesyats, M. M. Tsventoukh: IEEE Transactions on Plasma Science, 43(2015)3320-3322.

15) K. Yamazaki, E. Yamamoto, K. Suzuki, F. Koshiishi, S. Tashiro, M. Tanaka, K. Nakata: Science and Technology of Welding and Joining, 15(2010)40-47.

16) L. H. Phan, S. Tashiro, V. H. Bui, M. Tanaka: Smart Processing for Materials, Environment \& Energy, 7(2018)243-250.

\section{Mail Address}

Quang Ngoc TRINH ngoctq.hust@gmail.com Huy Le PHAN 1.phan@jwri.osaka-u.ac.jp Shinichi TASHIRO tashiro@jwri.osaka-u.ac.jp 